\title{
LA LIBERTAD DE EXPRESIÓN Y LA JURISPRUDENCIA DEL TRIBUNAL DE JUSTICIA DE LA UNIÓN EUROPEA
}

\author{
Miryam Rodríguez-Izquierdo Serrano
}

\begin{abstract}
Sumario: 1. Libertad DE EXPRESIÓN EN EL DERECHO DE LA Unión, EL Convenio Europeo, la CARTa de Derechos y el Tribunal de JustiCIA. 2. LA LIBERTAD DE EXPRESIÓN Y LA JURISPRUDENCIA DEL TRIBUNAL DE JUSTICIA. 2.1. Libertad de expresión, libertades económicas y libre competencia. 2.2. Libertad de expresión y pluralismo en el sector audiovisual. 2.3. Libertad de expresión y control transnacional de contenidos. 2.4. Libertad de expresión y publicidad. 2.5. Libertad de expresión y protección de datos. 2.6. Libertad de expresión y derechos de autor. 3. EL ARTÍCULO 11 DE LA CDFUE, INTERNET Y LA JURISPRUDENCIA DEL TJ.
\end{abstract}

\section{LIBERTAD DE EXPRESIÓN EN EL DERECHO DE LA UNIÓN, EL CONVENIO EUROPEO, LA CARTA DE DERECHOS Y EL TRIBUNAL DE JUSTICIA $^{1}$}

Como ocurre con el resto de los derechos fundamentales que tienen vigencia en el Derecho de la Unión, la primera aparición de la libertad de expresión en el escenario jurídico europeo se produjo en el seno de la jurisprudencia del Tribunal de Justicia. Y así, como todos los derechos que han tenido algún tratamiento en la jurisprudencia del Tribunal de Luxemburgo, haya sido el mismo sustantivo o tan solo tangencial, la libertad de expresión

${ }^{1}$ El presente trabajo se enmarca en el proyecto de investigación "Construyendo un estándar europeo de protección de los derechos fundamentales: de la Carta de Derechos Fundamentales de la Unión a las Constituciones, pasando por el CEDH» (DER201341303-P), financiado por el Ministerio de Economía y Competitividad. 
ha pasado en la doctrina del juez europeo por las etapas comunes a todos ellos. Primero han sido derechos que forman parte de las tradiciones constitucionales comunes de los Estados miembros y son, por tanto, principios generales del Derecho europeo ${ }^{2}$. En consecuencia, la libertad de expresión es acogida inicialmente por el Tribunal de Justicia como elemento indispensable de esas tradiciones y, casi sin solución de continuidad, o más bien superando resistencias iniciales, es puesta bajo el amparo del artículo 10 del $\mathrm{CEDH}^{3}$, mínimo común de la tradición común y siguiendo la interpretación que emana de la Corte de Estrasburgo ${ }^{4}$. Dentro de ese marco se ha mantenido la libertad de expresión en las alegaciones ante el Tribunal de Justicia, así como en las argumentaciones del mismo en respuesta y solución a los con-

${ }^{2}$ En la forja de los derechos fundamentales como principios generales del Derecho europeo el TJ siguió TJ a PESCATORE, cuando afirmaba en los años sesenta que, a pesar de la ausencia de derechos fundamentales en los Tratados, «en la realidad de las cosas, la constitución comunitaria contiene, al menos en germen, un sistema completo que puede servir de garantía a los derechos fundamentales». Pescatore, P., «Les droits de l'homme et l'integration européenne», Cahiers de Droit Européen, núm. 6, 1968, p. 636 (pp. 629673). Así fue como el TJ alumbró esos derechos-principios generales que, para el TJ, son elementos propios del ordenamiento jurídico europeo, independientemente de que para su obtención el juez de Luxemburgo tuviera que inspirarse en las tradiciones constitucionales comunes de los Estados miembros - que no en sus constituciones-, y en el Convenio Europeo de Derechos Humanos. Agudo Zamora, M., "La protección de los derechos fundamentales en la Unión Europea. Claves para entender la evolución histórica desde el Tratado constitutivo de la Comunidad Económica hasta el Tratado que establece una Constitución para Europa», Revista de Derecho Constitucional Europeo, núm. 4, 2005, p. 395, (pp. 373-427).

3 Ello a pesar de que en la primera sentencia en la que aparece una apelación al artículo 10 del Convenio, el TJ rehúsa entrar en la cuestión de la libertad de expresión alegando su falta de competencia para examinar la compatibilidad de una ley nacional con el $\mathrm{CEDH}$. Se trataba de una ley francesa que restringía temporalmente la reproducción en vídeo de producciones cinematográficas y que, a juicio del TJ y en la medida en que daba el mismo trato a las producciones nacionales y a las extranjeras, no era contraria a la libre circulación y, por otro lado, perseguía la finalidad razonable de promover las creaciones cinematográficas. Asuntos C-60/84 y C-61/84, Cinéthèque y otros vs. Fédération nationale de cinémas français y otros, Sentencia del Tribunal de Justicia de las Comunidades Europeas de 11 de julio de 1985, Rec. 1985, p. 02605. Como veremos, esa determinación del juez europeo es sustituida en otros casos posteriores por un escrutinio directo sobre la base del artículo 10 del Convenio. Las sentencias del TJ se citarán a pie de página con su referencia completa, mientras que en el texto principal se citarán con el número de asunto y con el título abreviado en cursiva.

${ }^{4}$ Aunque señalaba DíEz PICAZo que la ausencia de adhesión de la Unión al Convenio ha llevado a ciertas discrepancias en las respectivas jurisprudencias en relación con algunos derechos. DíEz PICAZo, L.M., «La relación entre la Unión Europea y el Convenio Europeo de Derechos Humanos», Teoría y Realidad Constitucional, núm. 15, 2004, p. 160, (pp. 159-170). 
flictos planteados, hasta fecha muy reciente. El cambio se ha dado cuando esas referencias recurrentes han pasado a estar acompañadas por invocaciones directas al artículo 11 de la CDFUE, cuando no por fin centradas y encuadradas en esta norma propia del Derecho de la Unión ${ }^{5}$.

La entrada en vigor de la Carta renueva, sí, la vigencia de los derechos fundamentales en el compleno normativo de la Unión e incide, también, en la jurisprudencia más reciente del Tribunal de Justicia sobre libertad de expresión, aportando nuevos perfiles. Esto último ocurre quizás no tanto por la diferencia entre las dicciones literales de ambos preceptos, que aun así existe $^{6}$, sino por el cambio de posición de esta libertad en el seno del complejo normativo de la Unión ${ }^{7}$. No obstante, siquiera por una razón temporal, aún

${ }^{5}$ Es algo que se observa en relación con otros derechos fundamentales, como es el caso del asunto Digital Rights, donde el TJ realiza un auténtico control de «constitucionalidad» de la Directiva, anulando partes de la misma por ser contraria los derechos a la intimidad y protección de datos de la Carta. En este asunto, sin embargo, el TJ no responde a la pregunta sobre la incidencia en la libertad de expresión del artículo 11 de la Carta por considerar que con sus respuestas a las cuestiones anteriores es suficiente. Asuntos C-293/12 y C-594/14, Digital Rights vs. Irlanda, Sentencia del Tribunal de Justicia de la Unión Europea (Gran Sala) de 8 de abril de 2014, aún no incluida en el repertorio de jurisprudencia.

${ }^{6}$ La dicción literal de ambos preceptos es la siguiente: «artículo 11 CDFUE, libertad de expresión y de información. 1. Toda persona tiene derecho a la libertad de expresión. Este derecho comprende la libertad de opinión y la libertad de recibir o comunicar informaciones o ideas sin que pueda haber injerencia de autoridades públicas y sin consideración de fronteras. 2. Se respetan la libertad de los medios de comunicación y su pluralismo»; «artículo 10 del CEDH, 1. Toda persona tiene derecho a la libertad de expresión. Este derecho comprende la libertad de opinión y la libertad de recibir o de comunicar informaciones o ideas sin que pueda haber injerencia de autoridades públicas y sin consideración de fronteras. El presente artículo no impide que los Estados sometan las empresas de radiodifusión, de cinematografía o de televisión a un régimen de autorización previa. 2. El ejercicio de estas libertades, que entrañan deberes y responsabilidades, podrá ser sometido a ciertas formalidades, condiciones, restricciones o sanciones previstas por la ley, que constituyan medidas necesarias, en una sociedad democrática, para la seguridad nacional, la integridad territorial o la seguridad pública, la defensa del orden y la prevención del delito, la protección de la salud o de la moral, la protección de la reputación o de los derechos ajenos, para impedir la divulgación de informaciones confidenciales o para garantizar la autoridad y la imparcialidad del poder judicial».

7 Según señala Linde PANAgua cuando categoriza los derechos de la Carta en función de su relación con las competencias de la Unión, el alcance del derecho del artículo 11 de la Carta sería el mismo que el del artículo 10 del CEDH. Linde PANAGUA, E., «El ámbito de aplicación: el talón de Aquiles de la Carta de Derechos Fundamentales de la Unión Europea», Revista de Derecho de la Unión Europea, núm. 15, 2008, p. 39, pp. 27-44. Sin embargo, como se verá al final de este trabajo, se aprecia una cierta inflexión en la línea argumental del Tribunal de Justicia en relación con la libertad de expresión una vez incorporada la Carta al Derecho de la Unión, debido a ese cambio de posición del que hablába- 
queda mucho para que ese artículo 11 de la Carta alcance el volumen de citas que en un repaso cronológico acumula el artículo 10 del Convenio. En cualquier caso, la libertad de expresión y la jurisprudencia del TEDH ya habían venido sirviendo, y con solvencia, como parámetro de escrutinio de la adecuación iusfundamental de restricciones y afectaciones de los derechos de comunicación y opinión en el ámbito de aplicación del Derecho de la Unión. Y esto ha sido así porque, aunque la Unión no tenga competencia directa sobre derechos fundamentales ${ }^{8}$, cuestión que tras la entrada en vigor de la CDFUE queda expresamente aclarada mediante el artículo 51.2 de la mis$\mathrm{ma}^{9}$, lo cierto es que más de un ámbito de competenia europeo de dimensión económica ha probado tener incidencia indirecta sobre la libertad de expresión, mientras que más de dos, como la protección de datos o la propiedad intelectual, la afectan de manera especial. En esa medida, quizás los perfiles del reciente cambio en el parámetro de control, con el flamante artículo 11

mos. En cierto sentido, nos referimos a algo que ponía en evidencia DíEz PICAZo cuando señalaba la falta de adhesión de la Unión al Convenio y cómo tal falta repercutía en la posición de los derechos fundamentales en la Unión. Decía el autor que la caracterización de los derechos fundamentales como principios generales agotaba la operatividad de los mismos en el derecho derivado y que esa realidad sería bien distinta si los derechos emanaran de manera directa de una adhesión al Convenio. DíEz PICAZO, L.M., «La relación entre la Unión Europea y el Convenio Europeo de Derechos Humanos», op. cit., p. 161. Sobre las relaciones entre los dos instrumentos, Carta y Convenio, véanse, entre nosotros y entre la abundante producción científica sobre la materia, el trabajo iniciático, con la Carta de Niza acabada de alumbrar, de Alonso GARCíA, R., «El triple marco de protección de los derechos fundamentales en la Unión Europea», Cuadernos de Derecho Público, núm. 13, 2001, pp. 13-43; el reciente, ya con la Carta y el Tratado de Lisboa en plena vigencia, de Gordillo PÉrez, L. I., Constitución y ordenamientos supranacionales, Centro de Estudios Políticos y Constitucionales, Madrid, 2012, pp. 101 y ss; o el que reflexionaba sobre el estado de la cuestión en aquel momento de tránsito del Tratado Constitucional de Álvarez-Ossorio Micheo, F., «El Sistema Multinivel de Protección de Derechos Fundamentales. Un análisis desde la Carta de Derechos Fundamentales de la Unión Europea», en CARMona Contreras (dir.), La Unión Europea en Perspectiva Constitucional, Cizur Menor, Thomson-Aranzadi, 2008, pp. 113-126.

${ }^{8}$ Como explica Gordillo Pérez: «el que la Comunidad tenga la obligación de respetar los derechos del hombre no implica que disponga de competencia para adoptar regulaciones específicas en este ámbito. En efecto, la carga que asume la Comunidad es la de asegurarse de que a la hora de aprobar una norma no se ven afectados los derechos humanos». GoRDILlo PÉReZ, L., Constitución y ordenamientos supranacionales, op. cit., p. 132.

9 Biglino CAMPos explica el significado de dicha exclusión expresa, estableciendo una comparación inversa con lo ocurrido en Estados Unidos con la decimocuarta enmienda, dejando claro que se niega que los derechos sean «un título competencial autónomo, que habilite a la Unión para dictar normas destinadas exclusivamente a garantizar su protección». BigLinO CAMPOS, P., «Derechos fundamentales y competencias de la Unión: el argumento de Hamilton», Revista de Derecho Comunitario Europeo, núm. 14, 2003, p. 66, (pp. 45-68). 
vigente desde 2009, no sean tan llamativos como lo son otras cuestiones sobre las que vamos a llamar la atención y que justifican, o pretenden hacerlo, la manera en la que hemos estructurado este análisis.

Además de las cuestiones relativas al Convenio y la Carta, y a su interpretación por parte del juez europeo, en la jurisprudencia del Tribunal de Luxemburgo sobre libertad de expresión interesa observar otros dos aspectos: por un lado las situaciones de hecho que originan los conflictos en torno a las libertades de comunicación que se elevan ante el TJ; y por otro las normas europeas de aplicación a los conflictos que se plantean. Desde nuestro punto de vista, son esos dos factores los configuran una aportación diferencial del juez europeo a la doctrina sobre la libertad de expresión. Y los mismos se deducen de las normas de Derecho estatal y de Derecho europeo que se barajan en las alegaciones de parte, en los planteamientos prejudiciales de los jueces nacionales y, cómo no, en las respuestas del Tribunal de Justicia. Como se pondrá de relieve, los contextos fácticos y normativos de ponderación en los que se inserta la libertad de expresión en tal sede jurisdiccional son distintos de aquellos a los que la justicia constitucional nos tiene acostumbrados ${ }^{10}$.

Lo habitual en los conflictos referentes a esta libertad pública, al menos en la jurisprudencia más conocida de nuestros Tribunales Constitucionales o del Tribunal Europeo de Derechos Humanos, es encontrarnos ante una de estas dos situaciones: por un lado, una situación en la que la libertad de expresión, o cualquier otra libertad comunicativa ${ }^{11}$, está en un vértice, mientras

10 Aunque algunos de estos «nuevos conflictos» sí son rastreables en la jurisprudencia y en el debate doctrinal sobre la Primera Enmienda en Estados Unidos, por ejemplo los relativos a la tensión entre libertad de expresión y derechos de autor, de los que es caso de referencia la Sentencia del Tribunal Supremo de los Estados Unidos Eldred v. Ashcroft, 537 U.S. 186 (2003). Acerca de las novedades que han surgido en los conflictos habituales sobre libertad de expresión ante el Tribunal Constitucional español, véase el trabajo de VÁZQueZ ALONSO, V., «Trascendencia constitucional y libertades de expresión e información» en Morales ARRoyo, J. M. (dir.), Recurso de amparo, derechos fundamentales y trascendencia constitucional, Aranzadi, 2014, pp. 387-402.

11 No ignoramos las diferencias existentes entre las distintas libertades de comunicación pública, tanto en el reconocimiento formal de las mismas como en la jurisprudencia constitucional, señalada, entre muchos, por Bustos GisBERT en Bustos GisBERT, R., «El concepto de libertad de información a partir de su distinción de la libertad de expresión», Revista de Estudios Políticos, Nueva Época, núm. 85, 1994, pp. 261-289. No obstante, a los efectos del análisis que llevamos a cabo en este trabajo, la libertad de expresión se utiliza como tipo abstracto de todos esos derechos de libertad, las libertades de comunicación pública, siguiendo las ideas de este mismo autor en Bustos GISBERT, R., «Los derechos de libre comunicación en una sociedad democrática», en GARCía RocA, J. y SANTOLAYa Macchetti, P. (coords.), La Europa de los Derechos, Centro de Estudios Políticos y Constitucionales, Madrid, 2005, p. 537, pp. 529-563. El concepto «libertad de comuni- 
que los derechos de la personalidad -honor, intimidad y propia imagen- están en el otro, de manera que es necesario realizar un juicio de ponderación que facilite la decisión sobre el o los derechos a proteger, siendo así que los criterios de tal ponderación están determinados por factores como la relevancia informativa o la veracidad del contenido, la dimensión pública o particular de la persona aludida, la capacidad de difusión del medio transmisor o la neutralidad en la presentación de la noticia, entre otros; o, por otro lado, una situación en la que hay una injerencia en el ejercicio del derecho a la libre opinión o información a través de una actuación directa, o una afectación a su contenido a través de una regulación específica o relacionada con el ámbito de realización de la libertad. En la segunda situación, que caracteriza una afectación o vulneración del derecho derivada de la actuación de un poder público, lo que se exige es un juicio de constitucionalidad que aplique los criterios de escrutinio correspondientes, entre los que se encuentran, de nuevo entre otros, la necesidad de la medida, la medición de la proporcionalidad en el sacrificio del derecho, el respeto al contenido esencial o a los bienes y objetivos constitucionales protegidos por el derecho o, en los juicios más depurados, el efecto inhibitorio de la restricción ${ }^{12}$.

Sin embargo, cuando la libertad de expresión se esgrime ante el Tribunal de Justicia de la Unión Europea, la misma se enfrenta a situaciones bien distintas, sobre todo por ser situaciones en las que las que las competencias atribuidas a la Unión tienen un gran protagonismo y también porque es sencillo que actores privados, operadores económicos o usuarios de servicios, entren en el juego de las restricciones indirectas que amenazan la libre comunicación. Así, las libertades de opinión e información llegan a medirse, al igual que otros muchos derechos fundamentales de tradición constitucional

cación» -por su carácter inclusivo y por hacer referencia al proceso entero de la comunicación y no a uno solo de sus elementos-define mejor el contenido común de estas libertades. El adjetivo de «pública», añadido, hace referencia no a algo «oficial»o «relativo a los órganos de poder», sino que se utiliza como «lo contrapuesto a lo privado y secreto». Parafraseamos el trabajo de Torres del Moral, A. y Navas CAstillo, F., «Encuadramiento terminológico de las libertades informativas», en TORRES DEL MORAL, A. (dir.), Libertades informativas, Colex, Madrid, 2009, p. 17, pp. 15-69.

12 Aunque se ha llamado la atención acerca de la habitual confusión de técnicas de escrutinio, ponderación frente a test de convencionalidad, que en ocasiones se da, como ejemplo, en la jurisprudencia del TEDH. BARENDT, E., «Balancing Freedom of Expression and Privacy: The Jurisprudence of the Strasbourg Court», Journal of Media Law, núm. 1, 2009, p. 55, pp. 49-72. El por qué de esta confusión en la sede de Estrasburgo puede ser la posición de partida del derecho a la reputación, que en ocasiones es tratado como un interés particular en lugar de como un derecho protegido por el Convenio. SMET, S., «Freedom of Expression and the Right to Reputation: Human Rights in Conflict», American University International Law Review, Vol. 26/1, 2010, p. 201, pp. 183-236. 
común, con las libertades económicas, es decir, con las libertades de circulación del mercado europeo en sus distintas variantes ${ }^{13}$. También se ven encuadradas en contextos de ponderación predefinidos en regulaciones europeas aplicables, como ocurre con las directivas sobre protección de datos, comercio electrónico o derechos de autor. Y para nuestras libertades protagonistas, como factor diferencial, las fronteras estatales que marcan los márgenes de apreciación de lo necesario y lo proporcional, así como de los sistemas de comunicación pública tradicionales ${ }^{14}$, aparecen alteradas por obra y gracia de la unidad del espacio europeo en su dimensión económica, cuando no más allá de cuestiones de mercado ${ }^{15}$.

13 Señala SARrión Esteve que «si estudiamos los casos en los que el Tribunal de Justicia ha relacionado ambas categorías (libertades económicas y derechos fundamentales) podemos encontrar dos tipos de relación o interacción: una positiva o de apoyo; y otra negativa o conflictual». Como veremos algo más adelante, es exactamente lo que ocurre en los conflictos relativos a las libertades de comunicación pública. SARRIÓN ESTEVE, J., «Los conflictos entre derechos fundamentales y libertades económicas en la jurisprudencia del Tribunal de Justicia de la Unión Europea», Revista de Derecho Político, núm. 81, 2011, p.382, pp. 379-412.

${ }^{14}$ La dimensión intrínsecamente estatal de los sistemas de comunicación pública, marcada en su origen por las barreras físicas a la distribución de la prensa escrita, se reforzó por parte de los Estados con acuerdos de la Unión Internacional de las Telecomunicaciones para proteger la soberanía estatal sobre los mismos. Keller, P., European and International Media Law, Oxford University Press, Oxford-New York, 2011, p. 227 y p. 231. La Unión Europea, con la unidad de mercado, altera tales límites en Europa, siendo la prueba patente la regulación de la comunicación audiovisual, que arranca a finales de los ochenta con la Directiva de televisión sin fronteras. Posteriormente, internet acaba con las fronteras aún resistentes de los sistemas de comunicación pública estatales. Como expone Post «el ordenamiento jurídico internacional está fundado, en su base, en la existencia de un reconocimiento mutuo de las fronteras físicas que separan las comunidades legislativas soberanas e independientes - los estados nacionales- unas de otras. Estas fronteras importan en ese ordenamiento y hacen una función esencial. Pero en la red, la información se mueve de maneras que parecen prestar poca atención a esas fronteras, y proyectarlas sobre la actividad de la red es un reto profundamente difícil». Post, D. G., In search of Jefferson's moose. Notes on the state of cyberspace, Oxford University Press, New York, 2009, p. 163.

${ }^{15}$ La regulación del reconocimiento mutuo de sentencias civiles en el espacio de la Unión, en desarrollo de los preceptos de los Tratados relativos al Espacio de Libertad, Seguridad y Justicia, ha llevado a resoluciones por parte del TJ en las que establecen criterios de determinación de fueros jurisdiccionales para conflictos transnacionales entre libertades de comunicación pública y derechos de la personalidad que afectan, cuando no inciden de manera directa, en los propios criterios de ponderación entre unas y otros. Véanse las siguientes resoluciones: Asunto C-68/93, Fiona Shevill y otros vs. Presse Aliance S.A., Sentencia del Tribunal de Justicia de la Unión Europea (Sala Sexta) de 7 de marzo de 1994, Rec. 1995, p. 415. Asuntos C-509/09, eDate Advertising vs. X; y C-161/10, Olivier Martínez vs. GMN Limited, Sentencia del Tribunal de Justicia de la Unión Europea (Gran Sala) de 25 de octubre de 2011, Rec. 2011, p. 10269. Algunos tra- 
Son estas singularidades, como veremos, las que confieren especial relevancia al análisis de la jurisprudencia del Tribunal de Justicia sobre libertad de expresión ${ }^{16}$. Todo ello sin perjuicio, insistimos, de la atención debida a la entrada en vigor de la Carta de Derechos, con su artículo 11, y a la manera en la que la misma haya podido influir en la doctrina del juez europeo en lo que a los derechos de opinión e información se refiere.

\section{LA LIBERTAD DE EXPRESIÓN Y LA JURISPRUDENCIA DEL TRIBUNAL DE JUSTICIA}

\subsection{Libertad de expresión, libertades económicas y libre competencia}

Puede parecer extraño que el derecho a la libertad de expresión en ocasiones se encuentre inmiscuido en conflictos relacionados con las libertades de circulación, las míticas cuatro libertades comunitarias, y con la defensa de la competencia. La extrañeza se matiza si se trae a colación la faceta empresarial y la dimensión de «servicio», en su sentido económico, de los medios de comunicación social. Así, cuando los medios de comunicación cruzan las fronteras de los Estados miembros, las interferencias que se producen tienen repercusión tanto en los sistemas de protección del mercado como en los de transmisión y recepción de informaciones que pueden ser, o no, básicas para la creación de una opinión pública libre y plural.

En tal contexto, podemos señalar algunos casos en los que la relación entre la libertad de expresión y las libertades comunitarias es puesta de relieve en las cuestiones prejudiciales elevadas al Tribunal de Justicia. La conexión entre las libertades es, por tanto, central en la argumentación del caso.

bajos que analizan estas sentencias desde la perspectiva del Derecho Internacional Privado son los siguientes: De Miguel Asensio, P., «Competencia judicial y protección de los derechos de la personalidad en internet», La Ley, enero de 2012, consultado on line en $<$ http//:eprints.ucm.es >; TORRALBA MENDIOLA, E., «La difamación en la era de las comunicaciones: ¿Nuevas? perspectivas de Derecho Internacional Privado Europeo», InDret, $<w w w$. indret.com $>$, enero de 2012; o LORENTE MARTínEZ, I., «Lugar del hecho dañoso y obligaciones extracontractuales. La Sentencia del TJUE de 25 de octubre de 2011 y el coste de la litigación en internet», Cuadernos de Derecho Transnacional, núm. 1, vol. 4, 2012, pp. 277-301.

16 Para la elaboración del presente trabajo se ha seleccionado un repertorio de jurisprudencia del TJ en el que las referencias y alegaciones sobre la libertad de expresión son recogidas en alguna medida por el Tribunal en su motivación, aunque no siempre sean elementos fundamentales del fallo. Por otro lado, las resoluciones elegidas son en todos los casos sentencias que resuelven cuestiones prejudiciales, pues hemos considerado de especial interés aquellos conflictos que tienen su origen en conflictos concretos. Queremos subrayar, por tanto, que no se trata de un análisis de jurisprudencia que agote toda la casuística ni los registros interpretativos del TJ en materia de libertad de expresión. 
Por tanto, y así es como razona el TJ, en la medida en que sean casos que puedan resolverse sobre la base de los principios de libre circulación recogidos en el Tratado, no será necesario determinar si hay o no afectación a la libertad de expresión. En caso contrario, dependerá del contexto fáctico y normativo con el que se encuentre el Tribunal.

Dentro de ese esquema interpretativo que se acaba de esbozar hay, por consiguiente, modulaciones. Muy rotundo en ese sentido es el argumento del Tribunal de Justicia en el asunto C-352/85, Bond van Adverteerders/Holan$d a^{17}$. En el mismo hay una normativa holandesa que establece condiciones de emisión distintas para programas emitidos desde el extranjero, pero que usan las redes de cable local, y para las emisiones nacionales. Tales condiciones distintas son de dos tipos: una referida a la inclusión de publicidad directa y otra referida a la subtitulación que, indirectamente, destacaba mensajes publicitarios que aparecieran en los programas retransmitidos. Pues bien, para el Tribunal de Justicia tales condiciones son contrarias al principio de libre prestación de servicios y no pueden acogerse a ninguna excepción. En consecuencia, la invocación del artículo 10 del CEDH, efectuada por el juez remitente en sus preguntas prejudiciales, no es tomada en consideración a efectos de resolver las cuestiones principales, que ya han sido contestadas con la simple apelación a la libre circulación de servicios. Relacionada con esta, pero diferente, es la situación en la que la cadena de televisión TV10, instalada en Luxemburgo, pretende difundir contenidos en territorio holandés, como si de una cadena extranjera se tratase, cuando la realidad es que la ubicación de la empresa mediática en el Gran Ducado se ha hecho con la sola finalidad de burlar las restricciones que la legislación nacional, holandesa, pone a las cadenas locales con el fin de preservar el pluralismo informativo en ese país. Es la historia del asunto C-23/93, $T V 10^{18}$, en cuya sentencia el razonamiento del TJ tomó cauces distintos de los vistos en C-352/85. El juez europeo consideró que la política holandesa, encaminada a preservar el pluralismo en el mercado mediático estatal, era conforme con el Tratado, como excepción prevista por el mismo y como parte de la política interna sobre medios de comunicación. No se vulneraba, por tanto, la libertad intracomunitaria de prestación de servicios, pero tampoco la libertad de expresión, principio general del Derecho europeo y norma del CEDH, pues precisamente la finalidad de la política holandesa de medios de comunicación era proteger dicha libertad garantizando el pluralismo. Y en una línea argumental re-

17 Asunto C-352-85, Bond van Adverteerders vs. Holanda, Sentencia del Tribunal de Justicia de 26 de abril de 1988, Rec. 1988, p. 2085.

18 Asunto C-23/93, TV10 SA vs. Commissariaat voor de Media, Sentencia del Tribunal de Justicia (Sala Quinta) de 5 de octubre de 1994, Rec. 1994, p. 4795. 
lacionada, si bien en un supuesto de hecho algo diferente, está el asunto C-260/89, Elliniki ${ }^{19}$. En este se enjuicia la conformidad con el Derecho europeo de la situación, privilegiada por la ley griega, de la única empresa helénica de radiotelevisión, con derechos de emisión protegidos por un monopolio blindado. En ese caso, la libertad de expresión se consideraba aplicable, habiendo una relación directa con las normas del Tratado que protegen la libre competencia y la libre prestación de servicios. Para el juez europeo, si bien es cierto que hay ciertas excepciones en relación con estas libertades a las que pueden acogerse los Estados, dichas excepciones, en la medida en que establezcan obstáculos a la libre prestación de servicios, deben ser acordes con los derechos fundamentales, en este caso la libertad de expresión, como parte de las tradiciones constitucionales comunes de los Estados miembros y tal y como vienen recogidas en el artículo 10 del Convenio ${ }^{20}$. El TJ deja al juez nacional la valoración de tal conformidad.

Más delicado, y de distinto signo, es el asunto que se baraja en el caso C-159/90, Grogan ${ }^{21}$, relacionado con la libre prestación de servicios entre Estados miembros, pero sobre todo con una serie de folletos distribuidos en Irlanda por asociaciones de estudiantes. Los folletos informaban sobre clínicas, sitas en territorio del Reino Unido, donde poder realizar una interrupción del embarazo, algo prohibido, y a nivel constitucional, en territorio irlandés. Para el TJ, si bien los servicios ofertados por las clínicas se trataban, en efecto, de actividades protegidas por la libre prestación, el hecho de que la distribución de los folletos la hicieran estudiantes, sin ánimo de lucro, y sin ninguna conexión contractual ni comercial con las clínicas publicitadas, sacaba el asunto del ámbito de aplicación del Tratado. Y, en consecuencia, el juez europeo dejaba sin respuesta la cuestión relativa a la compatibilidad de la prohibición irlandesa con la libertad de expresión recogida en el CEDH.

Por lo visto hasta ahora, cuando la libertad de expresión aparece mezclada con elementos básicos de la integración económica, la pauta común parece ser la delimitación de hasta qué punto el asunto incide realmente, o no, en esos elementos básicos. En función de tal delimitación, una vez afirmada la competencia, el TJ entra a valorar el papel de la libertad de expresión en el

19 Asunto C-260/89, Elliniki Radiophonia Tiléorassi AE y otros vs. Dimotiki Etairia Pliroforissis y otros, Sentencia del Tribunal de Justicia de 18 de Junio de 1991, Rec. 1991, p. 2925.

${ }^{20}$ SARrión EsteVe, J., «Los conflictos entre libertades económicas y derechos fundamentales en la jurisprudencia del Tribunal de Justicia de la Unión Europea», Revista de Derecho Político, núm. 81, 2001, p. 382, pp. 379-412.

${ }^{21}$ Asunto C-159/90, The Society for the Protection of Unborn Children Ireland Ltd vs. Stephen Grogan y otros, Sentencia del Tribunal de Justicia de 4 de octubre de 1991, Rec. 1991, p. 4685. 
conflicto concreto, pero solamente lo hace si con la preceptiva y previa valoración de los referidos elementos básicos aún es posible que la libertad de expresión aporte un matiz adicional al caso. Sin embargo, en el asunto C-368/95, Familiapress ${ }^{22}$, que versa sobre difusión de publicaciones periódicas alemanas en territorio austriaco, el TJ va algo más allá. Vamos a verlo. La ley austriaca de defensa de la competencia prohíbe que se oferten bienes o servicios a los que se les vincule un premio sin ningún tipo de contrapartida. La publicación alemana que se difundía en Austria realizaba tal actividad, ofreciendo recompensas económicas para los que resolvieran ciertas adivinanzas y crucigramas. La cuestión prejudicial planteaba la posibilidad de que la ley austriaca fuera una medida de efecto equivalente a las restricciones a la libre circulación prohibidas por el Tratado, que solo son justificables por un objetivo de interés general. El Tribunal de Justicia admitió que la medida era restrictiva para el comercio intracomunitario, pero sobre todo para la libertad de expresión, no obstante lo cual procedió aplicar el test de necesidad y proporcionalidad del artículo 10 del Convenio en la medida en que la finalidad de la ley austriaca era, precisamente, favorecer el pluralismo mediático y con ello la libertad de prensa. El test de proporcionalidad, no obstante, no es directamente efectuado por el $\mathrm{TJ}$, quien sí que traza el camino que debe seguir el juez nacional para hacerlo: realizar un análisis del mercado nacional de prensa afectado y comprobar que no existen medidas menos restrictivas que la adoptada, que era la total prohibición, para lograr el objetivo perseguido. No hay que perder de vista que en este asunto las publicaciones periódicas no son consideradas en sí mismas como vehículos de formación de la opinión pública, sino como bienes de mercado, por lo que, desde esa perspectiva, la protección otorgada por el TJ a la libertad de expresión, en aras de la protección de la libertad de mercado, resulta ser bastante garantista.

Como último caso de esta sección, quizás más cercano a la libertad de reunión que a la libertad de expresión, consideraremos el asunto C-112/00, Schmidberger ${ }^{23}$. Es una sentencia en la que el Tribunal de Justicia aboga desde el principio por la ponderación favorable a las libertades de expresión y manifestación por una sencilla razón: los hechos de los que traen causa la cuestión prejudicial, que no son otros sino los incidentes derivados de una manifestación ecologista que durante treinta horas interrumpió el tráfico de una carretera austriaca. Una empresa de transportes, dedicada a llevar made-

22 Asunto C-368/95, Vereinigte Familiapress Zeitungsverlags vs. Heinrich Bauer Verlag, Sentencia del Tribunal de Justicia de 26 de junio de 1997, Rec. 1997, p. 03689.

${ }_{23}$ Asunto C-112/00, Eugen Schmidberger, Internationale Transporte und Planzüge vs. Republik Österreich, Sentencia del Tribunal de Justicia de 12 de junio de 2003, Rec 2003, p. 5659. 
ra de Alemania a Italia y acero de Italia a Alemania, se vio especialmente afectada por el corte de circulación y pidió a Austria una indemnización por la responsabilidad derivada del incumplimiento del Derecho comunitario, considerando que, al no prohibir la manifestación, las autoridades austriacas vulneraban la libre circulación de mercancías. En este asunto el TJ recurre de nuevo a los cánones interpretativos del TEDH, apelando a los márgenes de apreciación nacionales en materia de restricciones en el ejercicio de derechos fundamentales y, por otra parte, realiza él mismo el test de proporcionalidad determinando que el objetivo de los manifestantes no podía alcanzarse con medidas menos restrictivas de los intercambios comunitarios y, en consecuencia, de alguna manera acaba ponderando a favor de las libertades de reunión y expresión y en detrimento, en este caso, de la afectación a la libre circulación de mercancías, libertad que se da por afectada.

\subsection{Libertad de expresión y pluralismo en el sector audiovisual}

La protección del pluralismo de medios de comunicación en un contexto en el que la libre competencia es un principio fundamental, y que puede ir en detrimento de lo anterior, ha sido un elemento de contrapunto en la actividad reguladora de la Unión Europea desde la primera normativa relacionada con la televisión sin fronteras a finales de los ochenta. El carácter fundamental del pluralismo mediático se recoge en el artículo 11 de la Carta, confirmando la idea de que la libertad de expresión garantiza solo la posición de uno de los vértices del proceso comunicativo -el del emisor-, sino también la de los receptores, en aras de la construcción de una opinión pública libre y formada.

El Tribunal de Justicia también se ha encontrado con situaciones en las que había que hacer valer esos componentes consustanciales a los derechos de libertad comunicativa, en especial en relación con las comunicaciones audiovisuales. Ya en el apartado anterior hemos destacado algunos ejemplos, vinculados a la libre prestación de servicios y referentes a emisiones transnacionales y a empresas de comunicación audiovisual sitas en territorios de Estados miembros distintos de aquellos en los que se recibe la comunicación. Pero la casuística que ha llegado al TJ nos presenta otras temáticas, como la que incide en ciertas obligaciones de transmisión o «transporte» de contenidos -o must carry- que se imponen sobre las empresas que soportan y gestionan las infraestructuras del cable en los Estados miembros. Es lo que sucede en el asunto C-250/06, United Pan-Europe Communications Belgium ${ }^{24}$,

${ }^{24}$ Asunto C-250/06, United Pan-Europe Communications Belgium SA vs. Bélgica, Sentencia del Tribunal de Justicia (Sala Tercera) de 13 de diciembre de 2007, Rec. 2007, p. 11135 . 
que relata cómo el Estado belga distribuía las emisiones que debían ser transmitidas en función de criterios relacionados con la condición bilingüe del país. Habiendo un desacuerdo en este punto por parte de las empresas portadoras, que consideraban que tales criterios suponían una restricción a la libre prestación de servicios, el proceso prejudicial concluyó con la siguiente decisión por parte del juez europeo: el régimen de concesión belga podría considerarse como una excepción permitida por el Tratado a los principios generales relativos a la libre prestación de servicios ya que se trataba de la protección del interés general, concretamente en la garantía del pluralismo cultural e informativo propio del derecho fundamental a la libertad de expresión. Como en otras ocasiones, el TJ invitaba al juicio de proporcionalidad con un método de escrutinio en tres fases: las obligaciones de transmisión debían establecerse a través de procedimientos transparentes; la determinación de qué cadenas serían beneficiarias debían llevarse a cabo de acuerdo con criterios objetivos y no ser más de las necesarias para la garantía del pluralismo; y, finalmente, no podían contener criterios discriminatorios. En la misma línea, el asunto C-336/07, Kabel Deutschland Vertrieb ${ }^{25}$, resuelve un conflicto similar en la Baja Sajonia Alemana, con argumentos casi idénticos, pero con el matiz de que en este supuesto son de aplicación sendas Directivas europeas reguladoras de las comunicaciones electrónicas, y en concreto la que reserva a los Estados la posibilidad de establecer obligaciones de transmisión. No se trata, pues, de una excepción general del Tratado, sino de un elemento conformador del margen otorgado a los Estados para configurar las obligaciones de transporte. Es decir: si las obligaciones de transporte sirven al interés general, y si la Directiva incluye expresamente a la libertad de expresión como fin de interés general, entendiendo que se refiere a la libertad de los usuarios de recibir informaciones de carácter plural, las obligaciones de transporte establecidas por la regulación estatal serán acordes con el Derecho europeo, incluido el derecho a la libertad de expresión. Por lo tanto, en este caso la tensión entre la libertad empresarial del prestador de servicio y la libertad de expresión se resuelve dentro de un contexto normativo que, al margen y además de la obligada apelación al artículo 10 de Convenio, incluye en su propio seno los elementos de la ponderación. Eso sí, en este caso se introduce una salvedad importante, que es la obligación de transporte del suministrador de la infraestructura de cable que no puede nunca derivar en consecuencias económicas no razonables que deba asumir el mismo. Ese último balance, el de lo irrazonable de las cargas económicas de la obligación

${ }^{25}$ Asunto C-336/07, Kabel Deutschland Vertrieb und Service GmbH \& Co. KG vs. Niedersächsische Landesmedienanstalt für privaten Rundfunk, Sentencia del Tribunal de Justicia (Sala Cuarta) de 22 de diciembre de 2008, Rec. 2008, p. 10889. 
de transmisión, se deja en manos del juez nacional y constituye un elemento de especial interés, pues no solo deja claro que favorecer el pluralismo informativo y de contenidos no puede ser llevado más allá de ese límite, sino que propone un nuevo juicio de ponderación entre la libertad de expresión y los intereses comerciales de las empresas portadoras ${ }^{26}$.

El pluralismo del sector audiovisual es, según lo visto, un objetivo estatal que es respaldado por el Derecho europeo y que alcanza la categoría de objetivo de interés general conectado con el ejercicio de la libertad de expresión en su vertiente, sobre todo, pasiva. Es una concepción que, una década antes de las sentencias sobre los operadores de cable, ya está presente, por ejemplo, en el asunto C-148/91, Veronica Omroep Organisatie ${ }^{27}$. Ahí, una entidad holandesa de radiodifusión, Veronica, realiza una serie de actividades en Luxemburgo encaminadas a asesorar y montar una nueva emisora que podrá ser captada en Holanda. A la entidad Veronica se la sanciona conforme a la ley holandesa, que prohíbe actividades de tal tipo y desviar recursos a otros fines distintos de los estrictamente señalados en la ley de medios holandesa. Ante la posibilidad, de nuevo, de que la prohibición contravenga las libertades económicas, el TJ vuelve a señalar que se trataría de un objetivo acogido por el Derecho europeo, pues se trata de preservar el pluralismo en el sector audiovisual. En un sentido distinto, también es central el objetivo general de preservar el pluralismo mediático en el asunto C-288/99, Gouda ${ }^{28}$. La diferencia es que en este último caso el resultado de la ponderación es distinto,

${ }^{26}$ Es interesante observar la diferencia entre el escrutinio realizado por el Tribunal de Justicia y el realizado por el Tribunal Supremo de los Estados Unidos en un caso de idéntica factura: Turner Broadcasting System, Inc. v. FCC, 512 U.S. 622 (1994). El Tribunal Supremo estadounidense lo que hace es catalogar a la ley de protección al consumidor, que establece las obligaciones de transporte para los operadores de cable, dentro de la teoría de las restricciones neutrales a la libertad de expresión. Al ser una medida neutral, y no basada en el contenido, el test de constitucionalidad es menos exigente y está basado en el objetivo perseguido por la norma, que en el caso americano es nivelar o modular la competencia en el mercado televisivo, preservando el acceso a una televisión gratuita para el cuarenta por ciento de los ciudadanos que no disfrutaban de televisión por cable. En toda la argumentación del Supremo está presente la conexión de la libertad editorial del operador de cable con la imposibilidad de controlar los contenidos transmitidos, aunque el TS considera que no hay contradicción con la Primera Enmienda. Esa visión, la relativa a la libertad editorial del operador, se sustituyen en la jurisprudencia del Tribunal de Justicia por la de la libertad económica del mismo como prestador de servicios. Ese es el motivo por el que la salvedad que hace el TJ, «salvo cargas económicas irrazonables», o entra dentro de la visión del TS de los Estados Unidos.

27 Asunto C-149/91, Vereniging Veronica Omroep Organisatie vs. Commissariaat voor de Media, Sentencia del Tribunal de Justicia de 3 de febrero de 1993, Rec. 1993, p. 487.

28 Asunto C-288/89, Stichting Collectieve Antennevoorziening Gouda y otros vs. Commissariaat voor de Media, Sentencia del Tribunal de Justicia de 25 de julio de 1991, p. 4007. 
pues ese objetivo no justifica que se puedan imponer a operadores audiovisuales extranjeros requisitos legales relativos a la estructura empresarial de su organización, como tampoco justifica que se establezcan restricciones relativas a la publicidad si esas restricciones están encaminadas a proteger los intereses económicos de los operadores estatales en lugar de estar basadas en razones relacionadas con el pluralismo audiovisual.

\subsection{Libertad de expresión y control transnacional de contenidos}

El control del sector audiovisual por parte del Estado miembro acaba, por tanto, donde acaban los objetivos del pluralismo. Y, sobre todo, acaba donde termina la jurisdicción de ese Estado en materia de emisiones audiovisuales. En este sentido, es de especial interés, y merece este epígrafe aparte, el asunto C-244/10 $0^{29}$, Mesopotamia Broadcast. En el mismo se plantea hasta qué punto un Estado miembro, en concreto Alemania, puede aplicar restricciones propias de su idiosincrasia constitucional a emisiones extranjeras, danesas en el caso, prohibiendo actividades que contravengan el principio de entendimiento entre los pueblos. Para el Tribunal de Justicia, siendo así que la Directiva de televisión sin fronteras establece que la jurisdicción que vincula a una sociedad emisora es la del lugar donde tiene su sede, en este caso Dinamarca, Alemania no tenía capacidad para enjuiciar o controlar las emisiones de la cadena, ni para prohibirlas en Alemania, ni siquiera teniendo en cuenta que los mensajes difundidos, y motivo de controversia, eran clasificables, y así lo determina el propio TJ, dentro de la categoría de incitación al odio que sanciona la propia Directiva. Aunque la emisión nociva alcance el territorio alemán, solo en Dinamarca puede determinarse si, dentro del ámbito de aplicación de la Directiva, existe, o no, incitación al odio como tal. Otra cosa es, y así se señala al final de la sentencia, lo que pueda ocurrir en caso de que Alemania aplique restricciones a la sociedad emisora si se trata de actividades que entran dentro de ámbitos de actividad distintos de aquellos cubiertos por la Directiva y si las prohibiciones no afectan a la retransmisión en sí misma. El ejemplo que se da es el siguiente: proyectar los programas nocivos en un recinto público, un estadio deportivo, podría ser una actividad susceptible de ser restringida al quedar fuera del ámbito de aplicación de la Directiva.

En conclusión, un Estado miembro no puede alterar la libertad de las entidades audiovisuales extranjeras de emitir sin fronteras, pues esa libertad en la Directiva está conectada no solo con una libertad económica, sino precisa-

29 Asuntos C-244/10 y C-254/10, Mesopotamia Broadcast y Roj TV vs. Alemania, Sentencia del Tribunal de Justicia (Sala Tercera) de 22 de septiembre de 2011, Rec. 2011, p. 8777. 
mente, también, con la libertad de expresión. Sin embargo, el Estado es libre de impedir actividades relacionadas con esas emisiones que contravengan principios de orden constitucional, y restrictivos de los flujos de comunicación pública, siempre que dichas actividades no entren dentro del ámbito de aplicación de la normativa europea.

\subsection{Libertad de expresión y publicidad}

Otra de las materias sobre las que la Unión Europea tiene competencia y que puede hacer aflorar conflictos con la libertad de expresión es la publicidad comercial. Bien en relación con la protección de los consumidores, bien en relación con la garantía de la libre competencia, bien en relación con la recepción de emisiones televisivas, las regulaciones europeas que inciden en la publicidad han sido puestas en cuestión en alguna ocasión ante el Tribunal de Justicia por su posible contradicción con las libertades informativas. En general, la causa a favor del amparo de la publicidad comercial bajo el paraguas de la libertad de expresión está más bien perdida antes de comenzarla, al menos si se adopta la perspectiva clásica según la cual el mayor nivel de protección de tal libertad se relaciona con su contribución a la formación de la opinión pública. Eso sí, parece lógico que en todo caso haya que escrutar o ponderar si una restricción a la actividad publicitaria pudiese llegar a ser limitativa de las libertades de comunicación pública.

Ese es el sentido con el que la libertad de expresión ha aparecido alegada en algunos asuntos relativos a restricciones publicitarias ante el Tribunal de Justicia. Un caso claro es el C-71/02, Karner $^{30}$, en el que la legislación austriaca de publicidad prohíbe que se publiciten como bienes procedentes de la masa de una quiebra, que son muy golosos para los compradores, aquellos bienes que ya no están en tal masa, aunque tal fuera su origen. Para el Tribunal de Justicia dicha prohibición austriaca no vulnera la libertad de expresión en la medida en que el artículo 10 del Convenio permite excepcionarla y en especial hacerlo cuando esta no se ejerce en el sentido clásico arriba indicado. Al no tratarse de un debate de interés general, en el que la libertad de expresión alcanzaría un nivel máximo de protección, lo único que se requiere es cerciorarse de que hay proporcionalidad en la prohibición establecida, cosa que el juez europeo encuentra en el simple hecho de que la ley austriaca busca la protección de los consumidores y la lealtad en las transacciones comerciales, es decir, en una ponderación con los intereses protegidos por la norma.

${ }^{30}$ Asunto C-71/02, Herbert Karner Industrie-Auktionen GmbH vs. Troostwijk $\mathrm{GmbH}$, Sentencia del Tribunal de Justicia (Sala Quinta) de 25 de marzo de 2004, Rec. 20004, p. 3025. 
La del asunto Karner es la pauta general de la argumentación del TJ en asuntos sobre publicidad y libertad de expresión, que grosso modo son de dos tipos: los que se refieren a restricciones relacionadas con la publicidad de medicamentos, en los que la ponderación se establece en relación con la protección a la salud de los consumidores, y casi siempre se inclina a favor de esta última; y los que derivan de regulaciones sobre publicidad en emisiones televisivas, ya que tales regulaciones establecen topes máximos temporales de mensajes publicitarios en aras de la protección de los receptores de la información.

En el primer grupo se hallan las sentencias de los asuntos C-219/91, Teer Voort, C-316/09, Sharp \& Dohme, y C-421/07, Damgaard ${ }^{31}$. En común tienen dos cosas: que en todos ellos la cuestión de la libertad de expresión de presenta de forma bastante oscura, en relación con el concepto de publicidad y la interpretación de la Directiva que establece un código común para la comercialización de medicamentos; y que en ninguno de ellos encuentra el juez europeo vulneración o limitación de la libertad de expresión. Lo que sí se deduce de los tres, por lógica inversa, es que la publicidad comercial no puede ser restringida absolutamente sin chocar con los límites de esa libertad fundamental, si bien los escrutinios que se realizan en los diferentes casos son bastante superficiales. En el asunto C-219/91, Teer Voort, se pregunta si la definición de un producto como medicamento, siguiendo lo establecido en una Directiva, podría ser contraria a la libertad de expresión de un tercero no comerciante. En el C-316/09, Sharp \& Dohme, se especula sobre la aplicación de la Directiva que establece un código común para la comercialización de medicamentos, y restringe su publicidad comercial. Se trata del artículo 88 de la Directiva, que prohíbe la publicidad de los medicamentos que requieren prescripción médica, y de una información que reproduce en internet lo escrito en el prospecto de un medicamento de ese tipo. El Tribunal de Justicia elude abiertamente entrar a considerar si el artículo 88 de la Directiva es conforme o no con la libertad de expresión, considerando que no se trata de una cuestión prejudicial de validez sino de interpretación, y resuelve que la reproducción literal del prospecto o la fiel del envase del medicamento, accesibles a solicitud del interesado, no entraría dentro del ámbito de prohibición del artículo 88. Por fin, en el asunto C-421/07, el señor Damgaard alega que una condena penal por publicidad de medicamentos prohibidos en Dinamarca sería contraria a la libertad de expresión, a lo que el Tribunal de

31 Asunto C-219/91, Johannes Stephanus Wilhelmus Ter Voort, Sentencia del Tribunal de Justicia (Sala Quinta) de 28 de octubre de 1992, Rec. 1992, p. 5485; Asunto C-316/09, MSD Sharp \& Dohme GmbH vs. Merckle GmbH, Sentencia del Tribunal de Justicia (Sala Tercera) de 5 de mayo de 2011, Rec. 2011, p. 3249; Asunto C-421/07, Frede Damgaard, Sentencia del Tribunal de Justicia (Sala Segunda) de 2 de abril de 2009, Rec. 2009, p. 2629. 
Justicia responde con la aplicabilidad de la misma Directiva que el caso anterior y con la proporcionalidad de la sanción, que es escrutada directamente por el propio juez europeo al considerar que el objetivo de protección de la salud de los consumidores la hace, por sí misma, proporcional.

En el grupo de sentencias relacionadas con la frecuencia de la publicidad en emisiones televisivas, pueden señalarse las de los asuntos C-245/01, RTL Television, y C-234/12, Sky Italia ${ }^{32}$. Los resultados del escrutinio del TJ son aproximadamente los mismos que los obtenidos en relación con los medicamentos: la protección de los espectadores, defendiéndolos de una invasión de publicidad, justifica las limitaciones temporales en la emisión de la misma. Las limitaciones están permitidas en una sociedad democrática, siguiendo el artículo 10 del Convenio, si son proporcionales y en ambos casos lo son. En el asunto C-245/01, RTL Television, se trata de una serie de películas con interrupciones publicitarias programadas, que se venden así para televisión, cuya emisión es alterada al lanzarse en abierto. Por lo que a la libertad de expresión se refiere, lo único que llama la atención es el inciso en el que el TJ explica que una restricción que no incide en el mensaje, es decir, en el contenido, sino solo en la temporalidad de su emisión apenas tiene incidencia en el ejercicio de la libertad. En el asunto C-234/12, Sky Italia, se especula sobre si la normativa de publicidad televisiva italiana, que permite menos publicidad en las cadenas de pago, puede ser contraria a la libertad de expresión y a la libre competencia. En ambos casos el TJ concluye que no lo es, aunque en realidad el juez europeo pasa por delante de la cuestión de la libertad de expresión cuando se le plantea una posible incompatibilidad de la regulación italiana aplicable con el artículo 11 CDFUE. Para zafarse del espinoso asunto, que le hubiera obligado a realizar un control de iusfundamentalidad de una norma estatal, el TJ expone que le faltan datos sobre el mercado concreto, el audiovisual italiano, por lo que no puede determinar si esas restricciones publicitarias establecidas para las cadenas de pago, y no para las cadenas privadas, afectan a la libertad de expresión y al pluralismo mediático.

\subsection{Libertad de expresión y protección de datos}

La protección de datos de carácter personal tiene algo en común con la libertad de expresión: ambas gozan del estatus de derechos fundamentales.

${ }^{32}$ Asunto C-245/01, RTL Television GmbH vs. Niedersächsische Landesmedienanstalt für privaten Rundfunk, Sentencia del Tribunal de Justicia (Sala Quinta) de 23 de octubre de 2003, Rec. 2003, p. 12489; Asunto C-234/12, Sky Italia Srl vs. Autorità per le Garanzie nelle Comunicazioni, Sentencia del Tribunal de Justicia (Sala Segunda) de 18 de julio de 2013, pendiente de inclusión en el recopilatorio. 
Por supuesto lo hacen a nivel europeo, pues ambos se recogen en la Carta de Derechos, pero también al del constitucionalismo de los Estados miembros. Sea por méritos propios, sea por su carácter instrumental para la protección de otros derechos de la personalidad, lo cierto es que el habeas data ha alcanzado en el espacio constitucional europeo un importante grado de protagonismo, por no decir de protección, en el que las directivas relativas a la protección de datos han tenido mucho que ver $\mathrm{y}$, al menos en el caso español, se han superpuesto a una jurisprudencia previa sobre protección de datos que la ha elevado de garantía de otros derechos a derechos fundamental autónomo. Precisamente por ello, los conflictos entre protección de datos y libertad de expresión e información tienen en el Tribunal de la Unión Europea al intérprete de mayor autoridad, puesto que la jurisprudencia del TJ sobre la interpretación de las directivas es sin duda imprescindible para entender el funcionamiento de la protección de datos en el espacio europeo. La interpretación de la Directiva de protección de datos, en particular, ha demostrado ser el eje de argumentación del Tribunal de Justicia en los distintos conflictos que sobre el conflicto entre habeas data y libertad de expresión se han planteado.

Para arrancar podemos citar, el caso Lindqvist, C-101/0133, que nos lleva a Suecia, donde una catequista, quizás en ejercicio de sus libertades comunicativas, cuelga en la página web de su parroquia, que además estaba enlazada a la de la Iglesia sueca, información personal relativa a los distintos catequistas que colaboraban con ella. Su intención era facilitar las inscripciones de los catecúmenos y la organización de las actividades propias de la formación de los mismos, pero la señora Lindqvist fue denunciada por sus correligionarios y se le impuso una sanción por haber publicado aquella información sin consentimiento de los titulares de los datos. El Tribunal de Justicia, al ser preguntado sobre la corrección de tal sanción conforme al Derecho europeo, afirmó expresamente que el asunto requería una ponderación entre libertad de expresión, la de la señora Lindqvist, y la tutela de la intimidad de las personas cuyo nombre había sido incluido en la página web. La ponderación se efectúa, no obstante, sobre la base de los parámetros aportados por la Directiva. Así, al ser un tratamiento de datos inconsentido, y al ser datos referidos a la religión que están especialmente protegidos por la norma, la balanza se inclina desde el primer momento a favor de los catequistas. Sin duda no se trataba de cuestiones de relevancia pública general, y sin duda la señora Lindqvist tampoco era una profesional del periodismo. Por eso, en el contexto de referencia, y tratándose de catequesis y de listas informativas, una actividad particular sin dimensión económica, es llamativo que el TJ no considere ni el ámbito de proyección de la Directiva ni los objetivos de la misma, que, desde

33 Asunto C-101/01, Bodil Lindqvist, Sentencia del Tribunal de Justicia de la Unión Europea 6 de noviembre de 2003, Rec. 2003, p. I-12971. 
su punto de vista, no serían suficientemente atendidos si se ponderara de otra manera $^{34}$.

Caso distinto, en el que sí hay un tratamiento periodístico de los datos de carácter personal, es el del asunto Satakunnan, C-73/0735. Se trata de una publicación controvertida aparecida en el diario finlandés Veropörssi, en la que se desvela información fiscal relativa a varias personas que entablan un proceso judicial para proteger sus derechos. Cuando el asunto es elevado ante el TJ, de nuevo parece claro desde el primer momento que la ponderación entre libertades de comunicación pública y protección de datos es el centro del conflicto. La diferencia es que, en este supuesto, hay la transmisión de datos con fines exclusivamente periodísticos, aun realizadas con ánimo de lucro, por lo que estas se encuadran naturalmente en las excepciones y exenciones potenciales que para ese tipo de información se recogen en el artículo 9 de la Directiva de protección de datos. También afirma el TJ que la transmisión de información de interés público se considera efectuada con fines periodísticos independientemente del soporte, incluido internet, por el que se transmita. En este asunto, la sensibilidad de los datos es menor, al no estar tratada como tal en la Directiva, por lo que la balanza, en su inclinación, va en sentido distinto que en el caso anterior.

Por tanto, parece que cuando el artículo 9 de la Directiva hace posible que, por motivos relacionados con la libertad de información, se excepcionen las exigencias de la normativa de protección de datos, hace igualmente viable la ponderación de los derechos enfrentados en situaciones específicas. La confirmación de este proceder la encontramos en la reciente sentencia del asunto C-131/12, Google Spain ${ }^{36}$, que parte de la reclamación de un ciudadano español ante la Agencia de Protección de Datos contra Google y contra un diario nacional, con edición digital, por hacer accesible una información, publicada originariamente en 1998, que daba cuenta de la subasta de bienes muebles en la que dicho ciudadano se había visto inmerso a causa de un embargo por deudas. La deuda estaba liquidada hacía tiempo y la reclamación contra la editorial del diario fue desestimada al tratarse de prensa institucionalizada, siguiendo la directriz marcada en la Directiva. Sin embargo, la reclamación contra el motor de búsqueda pros-

${ }^{34}$ Gerrero Picó, M., «El derecho fundamental a la protección de datos de carácter personal en la Constitución Europea», Revista de Derecho Constitucional Europeo, núm. 4, 2005, p. 300, (pp. 293-332).

35 Asunto C-73/07, Tietosuojavaltuutettu vs. Satakunnan Markkinapörssi Oy y Satamedia $O y$, Sentencia del Tribunal de Justicia de la Unión Europea (Gran Sala) de 16 de diciembre de 2008, Rec. 2008, p. I-09831.

36 , Asunto C-131/12, Google Spain SL y Google Inc. vs. Agencia Española de Protección de Datos (AEPD) y Mario Costeja González Google Spain, Sentencia del Tribunal de Justicia (Gran Sala) de 13 de mayo de 2014, aún no incluida en el recopilatorio de jurisprudencia. 
peró, instándosele a adoptar las medidas necesarias para retirar los datos de su índice e imposibilitar el acceso futuro a los mismos. Como consecuencia de tal resolución, Google Spain interpuso el recurso administrativo que acabó como cuestión prejudicial ante el TJ. Y, en su sentencia sobre el caso, el TJ sentó algunos criterios de ponderación de derechos de especial interés para la libertad de expresión. En primer lugar, el juez europeo determinó que la Directiva de protección de datos era plenamente aplicable a la actividad de indexación llevada a cabo por el motor, aunque se tratara, como en el caso concreto, de información aparecida previamente en un medio de comunicación y amparada por una excepción legal. En consecuencia, para el Tribunal de Justica era evidente la responsabilidad del motor de búsqueda frente a las lesiones de los derechos de la personalidad, protegidos por los derechos de autodeterminación informativa, del ciudadano. En segundo lugar, el TJ aclaró que los derechos a ponderar en torno a estas cuestiones eran por un lado los del interesado, titular de los datos, y por otro los derechos a recibir información de los internautas, dejando al margen consideración alguna sobre el ejercicio por parte del motor de búsqueda de libertades informativas o de expresión. A Google solo se le atribuían intereses económicos. En tercer lugar, el Tribunal estableció que en la ponderación entre derechos dos aspectos eran igualmente determinantes: el perjuicio causado al titular de los datos y la relevancia pública del mismo, es decir, su proyección mediática. A mayor relevancia pública del titular de los datos, mayor sería el peso del derecho de los receptores de la información. Y viceversa. En cuarto y último lugar, el TJ afirmaba la existencia de un derecho al olvido para el titular de los datos en relación con la actividad de los motores de búsqueda. Ese derecho existiría siempre y cuando la ponderación previa de derechos en conflicto, los del titular de los datos frente a los de los internautas, receptores de contenidos, así lo hicieran deducir. Como puede observarse, el TJ introduce un nuevo modelo de ponderación para conflictos entre libertades comunicativas y protección de datos, situando en un vértice a los derechos de la personalidad y en otro a los derechos, difusos, de un público receptor a acceder a la información excepcionada por la Directiva ${ }^{37}$. Sin duda es algo de relevancia en la configuración de la dimensión subjetiva de la libertad de expresión, que no significa, por supuesto, que ese tipo de derechos difusos sea accionable ante los tribunales. Por ahora.

${ }^{37}$ Una interesante crítica a la manera en la que se presenta la ponderación en esta sentencia, contraponiendo derechos de privacidad con derechos de los receptores que, en la argumentación del TJ, son tratados como «interés del público» puede encontrarse en FRANTZIOU, E., «Further developments in the right to be forgotten: The European Court of Justice`s Judgment in case C-131/12, Google Spain, S.L. v Agencia Española de Protección de Datos», Human Rights Law Review, vol. 4, 2014, p. 9, (pp. 0-17). 


\subsection{Libertad de expresión y derechos de autor}

Por último, nos acercamos al sugerente escenario de colisión entre libertades comunicativas y derechos de autor, un conflicto que concita gran número de discusiones sobre los límites que los segundos pueden imponer sobre los primeros. A diferencia de lo que ocurre con la protección de datos de carácter personal, los derechos de autor no tienen el mismo rango que la libertad de expresión como derechos fundamentales. Por más que haya teorías que los conectan con la libertad de expresión artística, lo cierto es que solo en esa medida podría considerarse que los derechos de autor alcanzan tal nivel, pues, aunque a nivel europeo se los menciona expresamente en el artículo 16 de la Carta de Derechos, dicha mención se encuentra en sede de derecho de propiedad y no, como ocurre con la expresión artística en la Constitución Española, de libertades comunicativas.

El hecho de que la Unión haya llevado a cabo un desarrollo cualitativa y cuantitativamente importante de la protección de los derechos de autor, tiene como consecuencia que el Tribunal de Justicia haya tenido que resolver conflictos entre estos derechos y la libertad de expresión en más de una ocasión. Como ocurre en otros ámbitos de conflicto, también en la tensión entre propiedad intelectual y libertades de comunicación el TJ recurre a la idea de equilibrio entre las libertades de usuarios de las obras, que ejercerían la libertad de expresión, y los titulares de los derechos protegidos. Esto se comprueba inicialmente en el asunto C-479/04, Laserdisken $^{38}$, relacionado con la venta de DVD, y en el que se impugnaba la validez de la Directiva por considerar que se privaba al autor y a los receptores de las obras de su libertad de expresión al establecer el agotamiento de los derechos de autor en el consentimiento prestado para la primera venta. El TJ desestima tan pretensión bajo la consideración, en el caso del autor, de que ya ejerce su libertad con la primera cesión de derechos y, en el caso de los receptores, de que la potencial limitación de su derecho a recibir información encuentra justificación en la necesidad de proteger la propiedad intelectual. La ponderación, según se comprueba, no tiene apenas posibilidades de actuación ante tal tipo de impugnación.

Un paso más allá es el que da el TJ en el asunto C-145/2010, Painer $^{39}$. Los hechos se refieren a la publicación por parte de varios diarios alemanes y austríacos de la fotografía de una niña desaparecida. La finalidad de la publicación era dar a conocer el suceso y contribuir a la búsqueda de la niña, pero las imágenes concretas habían sido tomadas por una fotógrafa profesional,

${ }^{38}$ Asunto C-479/04, Laserdisken ApS vs. Kulturministeriet, Sentencia del Tribunal de Justicia (Gran Sala) de 12 de septiembre de 2006, Rec. 2006, p. 8089.

39 Asuntos C-145/10, Eva-Maria Painer vs. Standard VerlagsGmbH y otros, Sentencia del Tribunal de Justicia (Sala Tercera) de 1 de diciembre de 2011, Rec. 2011, p. 12533. 
estaban protegidas por derechos de autor, y en las publicaciones no se hizo referencia a tal autoría. La Directiva aplicable establece excepciones potenciales en materia de derechos de autor, entre otras, por cuestiones de seguridad pública. Esa fue la excepción a la que se agarraron los diarios demandados por considerar que, al hacer pública la foto de la niña, estaban realizando una acción relativa a la seguridad pública. El problema es que dicha excepción se refiere a la difusión de las obras protegidas por parte de las fuerzas de seguridad del Estado y no directamente por la prensa. Así, el TJ consideró que los diarios demandados no pueden acogerse a dichas excepciones, ni siquiera invocando el artículo 11 de la Carta de Derechos de la Unión, pues el mismo no otorga a la prensa la misión de proteger la seguridad pública. Lo llamativo del caso es que, si bien es cierto que la prensa no tiene esa misión constitucional por sí misma, el TJ sea reacio a concederle a la publicación de la foto el grado de protección frente a los derechos de autor propio de la información de relevancia o interés público. Otra cuestión es la de la veracidad, puesto que en esa línea sí que se perfila una protección indirecta a la actuación de la prensa por parte del juez europeo. En efecto, el hecho de que la fotografía hubiera sido distribuida por las fuerzas de seguridad no resultaba baladí, puesto que al ser así no solo era posible que la prensa colaborase con las autoridades en la tarea de seguridad pública, sino que también era excusable el hecho de que la fotografía hubiera sido publicada sin hacer referencia a la autoría de la misma, en la medida en que la fuente de la que había sido obtenida no hubiera facilitado tal referencia. Como puede deducirse del complejo razonamiento, la situación en la que queda la libertad de prensa frente a los derechos de autor es muy distinta de la que hubiera resultado en una ponderación no condicionada por los márgenes de la Directiva. No parece muy descabellado afirmar que una ponderación no condicionada podría haber tratado la publicación como un supuesto de ejercicio veraz y relevante de la libertad de información, cuyo alto valor como elemento imprescindible de la formación de una opinión pública libre habría avalado su carácter preferente. Es significativo que en este caso no se desarrolle el habitual escrutinio que, sobre la base del artículo 10 del Convenio, el Tribunal de Justicia efectúa en otros casos que hemos analizado anteriormente. No es fácil decir si esa ausencia se debe al factor diferencial que aportan los derechos de autor, como derechos de propiedad intelectual, o si la diferencia se encuentra en que esta sentencia ya se elabora en función de la apelación al artículo 11 de la Carta de Derechos Fundamentales de la Unión.

Sobre excepciones también trata la sentencia del asunto C-201/13 ${ }^{40}, D e c-$ kmyn, en este caso sobre la excepción que la Directiva de derechos de autor

${ }^{40}$ Asunto C-201/13, Johan Deckmyn y Vrijheidsfonds VZWvs. Helena Vandersteen, Sentencia del Tribunal de Justicia (Gran Sala) de 3 de septiembre de 2014, no incluida aún en el repertorio de jurisprudencia. 
admite para la difusión de obras que sean parodias realizadas en observancia de las buenas costumbres. Al parecer en un calendario avalado por un partido político se había incluido un dibujo de portada que, reproduciendo los personajes y actitudes de otro dibujo publicado en 1961, ironizaba sobre el alcalde de Gante y la manera en la que, supuestamente, este manipulaba a la población inmigrante de origen árabe o de raza negra. Resulta bastante claro para el Tribunal de Justicia que estamos ante una parodia cuya finalidad es expresar una opinión, permitiéndose el juez europeo, incluso, desarrollar el concepto de «parodia» como un concepto propio del Derecho europeo ${ }^{41}$. Siendo posible, por tanto, apelar a la excepción, le queda al TJ la difícil tarea de perfilar una particularidad muy llamativa del caso, pues desde el punto de vista del autor del dibujo original la parodia descrita tenía tintes discriminatorios, por razón de raza y religión, y eso le perjudicaba adicionalmente en la medida en que su obra, el dibujo original, podía acabar siendo asociada a ese mensaje discriminatorio. El TJ, sin embargo, no resuelve esa cuestión, sino que invita al juez nacional a tener en cuenta el necesario equilibrio entre los intereses del autor y los del usuario de la obra original, dejando abierta la posibilidad de inclinar la balanza hacia un lado o hacia el otro. No entran en su argumentación cuestiones referentes al valor preferente de la crítica política en la sociedad democrática, como no lo hicieron antes, en el asunto Painer, las relativas a la relevancia púbica de la fotografía controvertida.

En definitiva, parece que el ámbito de los derechos de autor es, junto con la protección de datos, el nuevo campo de batalla para las libertades de comunicación pública. Y resulta que el Tribunal de Justicia, en virtud de la competencia que sobre tales cuestiones le da su posición, tendrá mucho que decir sobre este tipo de conflictos, sobre todo cuando, como se verá a continuación, la batalla tenga que decidirse en el complejo, escurridizo, transnacional y multifuncional país de internet.

\section{EL ARTÍCULO 11 DE LA CDFUE, INTERNET Y LA JURISPRUDENCIA DEL TJ}

Como hemos podido comprobar, la libertad de expresión tenía ya toda una trayectoria como derecho fundamental perteneciente a las tradiciones consti-

${ }^{41}$ «La parodia tiene por características esenciales, por un lado, evocar una obra existente, si bien diferenciándose perceptiblemente de ésta, y, por otro, plasmar una manifestación humorística o burlesca. El concepto de «parodia», en el sentido de [la excepción de la Directiva], no se supedita a requisitos que impliquen la necesidad de que la parodia tenga un carácter original propio, más allá de la presencia de diferencias perceptibles con respecto a la obra original parodiada, pueda razonablemente atribuirse a una persona que no sea el propio autor de la obra original, incida sobre la propia obra original o mencione la fuente de la obra parodiada». Asunto C-201/13, Deckmyn, op. cit., párrafo 33. 
tucionales comunes de los Estados miembros, y como derecho reconocido por el Convenio, cuando la Carta de Derechos Fundamentales entró en vigor e introdujo, con su artículo 11, una definición específica de la libertad de expresión para el espacio de la Unión ${ }^{42}$. Si se toma en consideración la jurisprudencia más antigua al respecto del Tribunal de Justicia, y se la compara con la más reciente, nada parece haber cambiado. El juez europeo se ha acostumbrado a no tratar con los derechos fundamentales, y entre ellos la libertad de expresión, si no es en relación con las competencias de la Unión y en eso lo lógico es que, ahora con más razón, su posición ante el artículo 11 respete fielmente los límites marcados por el artículo 51 de la Carta: ceñir su interpretación sobre libertades de opinión y prensa a aquellos casos en los que realmente se estén ejerciendo competencias de la Unión o se esté en ámbito de aplicación del Derecho europeo; y no dar por asumidas competencias derivadas de los derechos fundamentales que no hayan sido atribuidas a la Unión.

Por su parte, en los ámbitos de competencia de la Unión que inciden en la libertad de expresión, el Tribunal de Justicia se adentrará en el fondo de los conflictos en la medida en que así esté previsto en la regulación europea aplicable, bien porque dicha regulación introduzca excepciones que contemplen la prioridad de las libertades informativas, bien porque de la misma se derive una exigencia de ponderación. Y, a su vez, esa regulación de ámbitos competenciales diversos, como la protección de datos o los derechos de autor, va a repercutir de forma directa sobre la interpretación y ponderación que el TJ haga de la libertad de expresión. No se barajarán, por tanto, criterios de escrutinio singulares derivados del artículo 11 de la Carta, que podrían dar valor preferente a las libertades informativas de una manera directa, sino que más bien se seguirán los parámetros de ponderación consignados en las regulaciones aplicables. El resultado de esto, si se sigue la pauta que se ha llevado hasta ahora, será que el Tribunal de Justicia mantendrá en sus escrutinios sobre libertad de expresión argumentos propios de la interpretación teleológica a la que nos tiene acostumbrados, con los cuales construye un muro de contención ante cualquier amenaza para la consecución de los objetivos del Derecho de la Unión. Pero puede ser que la aplicabilidad del artículo 11 de la Carta, combinada con situaciones inéditas, provocadas por los avatares de la comunicación a través de internet, traiga nuevas formas de razonamiento a la jurisprudencia del TJ.

Del mismo modo, a partir de ahora también será importante observar en qué medida las apelaciones al artículo 11 de la Carta van a ir sustituyendo a las del artículo 10 del Convenio. Teniendo en cuenta lo habitual que ha sido que el Tribunal de Justicia copie la dinámica de interpretación del TEDH,

${ }^{42}$ Nos remitimos a la nota 5 , en la que se recogen las dicciones literales tanto del artículo 11 de la Carta como del artículo 10 del Convenio, y a la reflexión que ahí se anticipa sobre la novedad del artículo 11. 
aplicando a las restricciones de las libertades de comunicación el test de necesidad y proporcionalidad, será importante analizar si el TJ modifica en alguna medida esa pauta ajena y si introduce alguna novedad que signifique la adopción de una doctrina propia sobre libertad de expresión.

En este sentido, es imprescindible hacer referencia a sendas sentencias relativamente recientes, que versan sobre derechos de autor en internet y requerimientos judiciales para la protección de la propiedad intelectual, en las que no se aplican los clásicos test del artículo 10 del Convenio, y sí se hace una lectura directa de la Carta. Una de ellas es la del asunto C-360/10, Sa${b a m^{43}}^{43}$ en la que, en relación con la interpretación de varias regulaciones sobre propiedad intelectual y comercio electrónico, se pregunta al TJ si un juez estatal puede dictar una orden de cesación, conforme a la legislación procesal estatal, que obligue a un intermediario de internet a implementar un sistema de filtrado de la información que se aloje en sus servidores. El fin de ese sistema de filtrado sería identificar los archivos que vulnerasen derechos de autor y propiedad intelectual y bloquear su procesamiento. En su respuesta, el juez europeo considera que tal actuación vulneraría la libertad de información, ya que el sistema no podría diferenciar contenidos lícitos e ilícitos y se acabarían bloqueando contenidos lícitos o libres de derechos de autor. Más refinado aún es el fallo del asunto C-314/12, Telekabel ${ }^{44}$, en el que se pide una orden judicial para bloquear el acceso de los internautas a un sitio web en el que se ofrecía material cinematográfico protegido por derechos de autor. El Tribunal de Justicia plantea en este caso, y más allá de los elementos normativos de las Directivas aplicables, que tiene que haber una armonización de los distintos derechos fundamentales protegidos por la Carta, entre los que están tanto la libertad de información como la propiedad intelectual. Habla el Tribunal de un justo equilibrio, exigido por el artículo 52 de la Carta, que permite, por una parte, que se adopten medidas de bloqueo, sin que las mismas puedan, por otra parte, llegar a ser privativas del derecho a acceder a información lícita por parte de los usuarios de internet. Ese es el ejercicio de ponderación que el Tribunal de Justicia invita a hacer al juez nacional y que supone, como se ha sugerido, una innovación sustantiva en la forma de proceder del juez europeo en cuestión de libertad de expresión. El camino para una jurisprudencia importante sobre los conflictos entre libertades de comunicación, protección de datos y derechos de autor en internet está abierto para el Tribunal de Luxemburgo.

${ }^{43}$ Asunto C-360/10, Belgische Vereniging van Auteurs, Componisten en Uitgevers CVBA (SABAM) vs. Netlog NV, Sentencia del Tribunal de Justicia (Sala Tercera) de 16 de febrero de 2012, Rec. 2012.

${ }^{44}$ Asunto C-314/12, UPC Telekabel Wien GmbH/Constantin Film Verleih GmbH y Wega Filmproducktionsgesellschaft $\mathrm{mbH}$, Sentencia del Tribunal de Justicia (Sala Cuarta) de 27 de marzo de 2014, aún no incluida en el recopilatorio. 
TITLE: Freedom of speech and the Case Law of the Court of Justice of the European Union.

RESUMEN: El artículo 11 de la Carta de Derechos Fundamentales incorpora formalmente a la libertad de expresión en el ámbito del Derecho de la Unión Europea. No obstante, como parte de las tradiciones constitucionales comunes de los Estados miembros, así como a través del artículo 10 del Convenio Europeo de Derechos Humanos, la libertad de expresión era ya un derecho fundamental europeo que se mezclaba con las libertades económicas, con regulaciones relacionadas con la comunicación audiovisual, con la protección de datos, con la propiedad intelectual y con el comercio electrónico. El presente artículo analiza la situación de la libertad de expresión en ese contexto normativo y en la jurisprudencia del Tribunal de Justicia de la Unión Europea.

PALABRAS CLAVE: Tribunal de Justicia de la Unión Europea; Libertad de expresión; Carta de Derechos Fundamentales de la Unión Europea; Convenio Europeo de Derechos Humanos.

ABSTRACT: Article 11 of the Charter of Fundamental Rights officially inserts freedom of expression in the scope of European Union Law. But this freedom was a European fundamental right already, as a part of the common constitutional traditions of the member states and also through article 10 of the European Convention of Human Rights. At EU level, freedom of expression has been mixed up with economic freedoms and competition law, as well as with regulations on audiovisual communications, on data protection, on intelectual property rights and on electronic commerce. This article analyses the situation of freedom of expression in such regulatory framework and in the case law of the European Court of Justice.

KEYWORDS: European Court of Justice; Freedom of expression; European Union Charter of Fundamental Rights; European Convention of Human Rights. 